Abstract ID: 93

\title{
Awareness of public in Kuantan on the roles and services provided by an audiologist
}

\author{
Nor Azri Azrin | Nur Ain Othman | Nur Hanisah Tukiran \\ Department of Audiology and Speech Language Pathology, Kulliyyah of Allied Health Sciences, \\ International Islamic University Malaysia
}

Introduction: Prevalence of disabling hearing loss among Malaysians is $5 \%$, according to Malaysia's Health Survey. The need for audiological service is clear. Despite the urgencies in hearing-related health issues, there is not much known about public awareness of the audiologist's role and services especially in Kuantan. This current study aims to explore this matter. Methods: Self-administered questionnaires consisting 2 sections were distributed randomly in public in Kuantan. Section A comprises of participants' sociodemographic information (i.e. gender, race, age, occupation, and level of education). Section B consists of Part a: Familiarity with Audiological Services, Part b: Knowledge on Role and Services of Audiologists, and Part c: Source of Information. 56 respondents were involved. Results: $66.07 \%$ of subjects $(n=37)$ claimed they knew about the audiologist existence in Malaysia and $33.93 \% \quad(n=19)$ claimed otherwise. There is no significant association between sociodemographic information with the awareness on audiologist existence and also the knowledge that respondents were regarding audiologist role and services. There is a significant association between participants' awareness on the audiologist existence in Malaysia with their familiarity with audiologists $(p$-value $=0.006)$. There is also a significant association between the responder awareness with their knowledge on audiologist role and services ( $p$-value $=0.006$ ). However, there is no association between respondents' familiarity with audiologists and their knowledge on audiologist role and services. Conclusions: Public awareness on audiologists role and services in Kuantan is fair.

KEYWORDS: audiologist; awareness; role; services; public 